\title{
Variation of Thermal Conductivity of Polystyrene Insulation Material Under Different Operating Temperatures and Moisture Contents
}

\author{
Maatouk Khoukhi
}

\begin{abstract}
Utilizing thermal insulation in the building envelope, in harsh climates, will considerably reduce the heat gain through the envelope of the building and consequently its energy consumption. The performance of thermal insulation material is mainly determined by its thermal conductivity $(k)$, which describes the ability of heat to flow cross the material in presence of gradient of temperature. In practice, the $k$-value is normally evaluated at $24^{\circ} \mathrm{C}$ (i.e., $\mathrm{k}_{24}$ ) according to relevant ASTM standards. Actually, the thermal insulation materials when used in building envelope are exposed to significant and continuous temperature change. Moreover, the material moisture content, which is influenced by the ambient humidity level, may significantly affect the k-value of the insulation material. The main objective of this paper is to investigate the effect of the operating temperature and the moisture content on the thermal conductivity of various densities of polystyrene insulation material, which is widely used in Oman under hot-humid climate.
\end{abstract} words)

Keywords - component, formatting, style, styling, insert (key

\section{Introduction}

In Oman, buildings account for a major share of electric energy consumption. In some region with less industrial activities, more than $70 \%$ of electric energy is consumed by buildings [1]. Due to the prevailing harsh climate condition, the majority of the consumed energy is used by the airconditioning and ventilation systems [2]. The amount of this energy is directly related to the heat transfer by conduction through the building envelope. This can be reduced by using effective thermal insulation material in the building envelope.

Most buildings in Oman are not well insulated due to the absence of regulation and standards. Therefore, buildings consume more energy than is necessary for their operation. For skin-load dominated structures in Oman, using appropriate thermal insulation is the first step achieving energy efficient buildings. Thermal insulations are materials or combination of fibrous materials, particulate, film or sheet, block or monolithic, open cell or closed cell that can be chemically or mechanically bound or supported to retard the rate of heat flow by conduction [3].

Dr. Maatouk Khoukhi

College of Engineering / Sultan Qaboos University

Sultanate of Oman
Thermal insulation materials like other natural or manmade materials exhibit temperature dependence properties that vary with the nature of the material and the influencing temperature range. For most materials, the value of thermal conductivity increases as the influencing temperature increases. Therefore, temperature dependent thermal conductivity is an empirical relationship that is based on experimental data [4]. For a given aged material sample, the average conductivity mainly depends on density $(\rho)$, temperature (T) and water content (w) [5].

The impact of operating temperature on the thermal performance of insulation materials has been the subject of many studies. Budaiwi et al. have investigated the impact of operating temperature on thermal conductivity, and consequently the change in the building envelope-induced cooling load. Thermal conductivities of various insulation materials were measured at different operating mean temperatures. Results indicate that a higher operating temperature is always associated with higher thermal conductivity [6]. Aldrich and Bond have investigated theoretically and experimentally the thermal performance of rigid cellular foam under different temperature [7]. The result showed significant variations in the k-value with operating conditions. Another set of experiments was conducted on the thermal performance of fiberglass using an attic test module in a guarded hotbox facility [8]. The result shows that at large temperature differences the thermal resistance was less about $35-50 \%$ than that at small temperature differences. The impact of temperature difference on the thermal conductivity of some insulation materials produced by Saudi insulation manufacturers has also been investigated [9].

In addition to operating temperature, the material moisture content, which is influenced by the ambient humidity level, is another major factor affecting the thermal conductivity on insulation material [10]. Investigation of the performance of polyurethane insulation [11], fiberglass [12] and mineral wool [13] used on heating and cooling pipes subjected to underground water attack were conducted. The impact of thermal conductivity change of moist fibrous insulation on energy performance of buildings under hot-humid conditions has been investigated by Budaiwi and Abdou. The result showed that the moisture behavior of the insulation layer is tangibly influenced by the moisture characteristics of other wall components [14].

Consequently, both operating temperature and water moisture factors have a significant influence on the thermal performance of insulation materials. The objective of this research is to investigate the combined effect of changes in 
operating temperature and moisture content on the variation of thermal conductivity of locally produced polystyrene insulation material with different densities.

\section{Experimentation}

\section{A. Measurement Apparatus and Procedure}

The guarded hot plate method has been used to measure the heat through the sample. In this method a heater is fabricated to the surface dimensions of the specimen and two identical specimens are used as the heater is placed in the middle (see Fig. 1). This method allows us to safely assume that the power produced by the heater is distributed evenly and same amount of heat is passed through by each sample. Apart from the two surfaces all other surfaces are insulated hence to ensure that no heat will pass through to safely assume that only the main required surfaces will conduct heat.

A known voltage and current is then supplied to the heater and the temperature in the surface of the heater (inner surface of specimen) is measured. Similarly the temperature of the outer surface is also measured for the increment in temperature till it reaches the steady state. Then the temperature difference is taken and calculations are performed.

Since the thermal conductivity changes with the ambient (surrounding) temperature, all necessary precautions has to be taken to ensure that it will remain almost same throughout testing time. For this purpose a special temperature control chamber is fabricated to maintain and to adjust the temperature as for the testing requirement. This control chamber as shown by Fig. 2 is made by wood and insulated with high temperature heat proof material to prevent heat loss from the box.

A Water reservoir as shown in Fig. 3 is used in coordination with a chiller and a heater embedded water circulator pump. An aluminum radiator is installed on the back plate of the box. Water supply circulates through the radiator hence emitting the temperature of the water to the chamber. A fan is mounted on the radiator to allow the temperature to be more efficiently extracted and to be circulated evenly throughout the chamber. By changing the temperature of water, the required ambient condition has been achieved so that the specimens can be tested for thermal conductivity at different stable conditions.

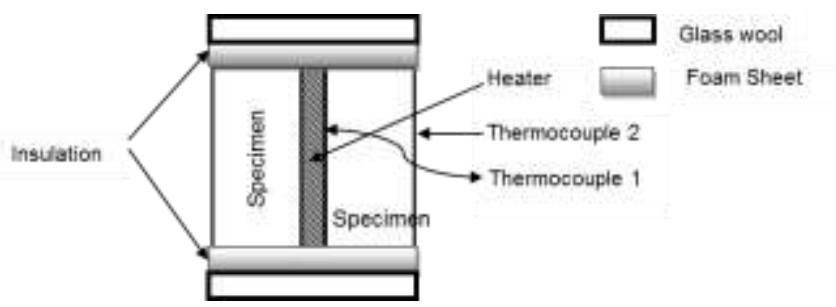

Fig. 1. Guarded hot plate

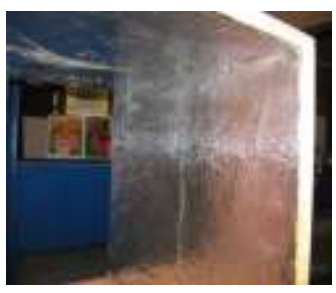

Fig. 2. Wooden box fabricated with heat proof material

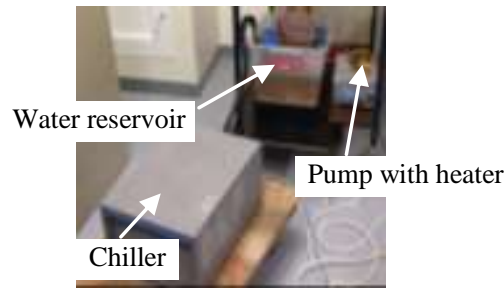

Fig. 3. Experimental set up with water reservoir, chiller, pump and heater

The chiller is only used to for the testing of $10^{\circ} \mathrm{C}$ along with the heater pump to provide more stability. All the other temperature conditions of $24^{\circ} \mathrm{C}, 37^{\circ} \mathrm{C}$ and $43^{\circ} \mathrm{C}$ were achieved by using the heater with the pump only. Although the temperature controlling of the heater is accurate, a separate thermometer is used for visual inspection of the reservoir's water temperature to have more confidence.

In order to get the sample moisturized an ultrasonic humidifier is utilized. An ultrasonic humidifier uses a piezoelectric transducer vibrating at high frequency. When water drops and hits the element, which vibrates at high frequency, it creates a mist of water droplets that gets evaporated into the Air. The circuit of the humidifier is electronically modified to suit the desired rate of mist that gets evaporated (see Fig. 4).

As illustrated in Fig. 5, a small acrylic chamber is furnished, to trap the moisture so our sample can be placed in it. Sample is elevated via a metal mesh, in terms to have minimal contact with the chamber surface to ensure the homogeneous distribution of moisture around the sample (see Fig. 6). Once the humidifier is started, the opening of the chamber was covered with a piece of foam. A small opening was kept so that the excess moisture can be exited through the chamber. Within seconds the chamber is filled with moisture and the sample is weighed time to time to ensure the weight gain to the proportion of the moisture percentage that is required.



Fig. 4. Ultrasonic humidifier 
Proc. of the Second Intl. Conf. on Advances in Mechanical and Automation Engineering - MAE 2015

Copyright (C) Institute of Research Engineers and Doctors, USA .All rights reserved.

ISBN: 978-1-63248-045-3 doi: 10.15224/ 978-1-63248-045-3-37

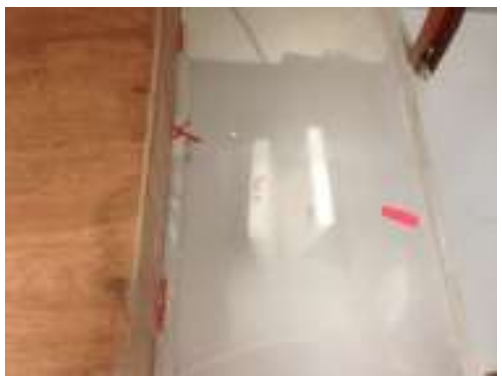

Fig. 5. Chamber filled with moisture

\section{B. Specimen Preparation}

A heater was prepared by using a nicrome wire and a thin mica sheet as a base. Two identical samples were cut to have the same area of the heater. Then the heater is placed in between the samples along with a thermocouple in the middle to measure the temperature of the heater (identical to the heat inside the specimen). A second thermocouple was used outside of the specimen in line with the first one to measure the temperature rise in the outer surface. Another thermocouple is used to measure the ambient temperature of the chamber to verify the testing environment.

The surrounding surfaces of the samples were insulated using glass wool and foam sheet to prevent heat loss assuming that all the heat generated via the heater is transferred to the required surfaces of the specimen. Two aluminum plates were used along with a C-Clamp, to ensure samples have full contact with the heater. The power to the heater is supplied via a variable power supply with very high accuracy and stability. Voltage and current drawn by the heater is displayed directly in the power supply, so the power generated via the heater can easily be calculated. All the thermocouples were connected to a data logger which measures the values at 15 second intervals.

The data from the logger is displayed directly in the computer which allows real time chart plotting to simply identify when the steady state is achieved. Then the final values of the thermocouples were taken to calculate the temperature gradient and to calculate the thermal conductivity. Every sample was tested at 4 different environments and 3 trials were run at a single environment to verify the accuracy of the setup.

\section{Results and Discussion}

The designed experimental apparatus based on the guarded hot plate principle has been tested and calibrated using the known thermal conductivity values of three samples (HD, UHD and SHD) run at $10^{\circ} \mathrm{C}$ provided by another company. The thermal conductivity of the samples at $10^{\circ} \mathrm{C}$ is presented in Table 1 as reference values. To ensure accuracy, the samples have been tested three times over an extended period and the average values are shown in Table 1.

It can be seen that the difference between the average measured thermal conductivity and the reference values of the three samples is within the acceptable range of accuracy. SHD sample presents less difference with $1.5 \%$. Therefore, the designed apparatus is considered accurate enough to carry on the rest of the measurement.

The impact of operating temperature on the thermal conductivity values of polystyrene insulation material with four different levels of densities is illustrated in Fig. 7. It shows that thermal conductivity values of the four samples are affected in varying degrees with operating temperature. In all cases, higher temperature leads to higher thermal conductivity. The thermal conductivity also decreases with the increase of the density of the sample.

The effect of the moisture content of the k-value of polystyrene insulation with different densities at 10, 24, and $28^{\circ} \mathrm{C}$ was investigated using the developed apparatus described previously. However, it has been noticed that the change of the moisture content at different operating temperature has a very small effect on the $k$-value for the polystyrene insulation material with HD, UHD, and SHD densities. Indeed, they are more impermeable to water and moisture transfer due to their high densities.

Therefore, the investigation of the effect of the moisture content on k-value of the polystyrene insulation was limited to the LD density. The best-fit linear relationships between kvalue and moisture content at a specified operating temperature are shown in Fig. 8. It was difficult to get any significant data at high operating temperature beyond $28^{\circ} \mathrm{C}$ due to the evaporation process in the sample during the measurement procedure.

In order to compare thermal conductivity variations for the different samples the measured $\mathrm{k}$-values and the resulting operating temperature is established. This best-fit linear relationship is shown in Fig. 9.

TABLE I. DIFFERENCES IN THERMAL CONDUCTIVITY VALUES FOR THE THREE SAMPLES

\begin{tabular}{|c|c|c|c|}
\hline Samples & $\begin{array}{l}\text { Average measured } \\
\text { thermal conductivity } \\
{\left[\mathbf{W m}^{-1} \boldsymbol{K}^{-1}\right]}\end{array}$ & $\begin{array}{l}\text { Thermal conductivity } \\
\text { reference }\left[\mathbf{W m}^{-1} \boldsymbol{K}^{-1}\right]\end{array}$ & $\begin{array}{c}\text { Differences } \\
{[\%]}\end{array}$ \\
\hline HD & 0.03588 & 0.035 & 2.5 \\
\hline UHD & 0.03329 & 0.032 & 4 \\
\hline SHD & 0.03046 & 0.03 & 1.5 \\
\hline
\end{tabular}

Fig. 6. Metal mesh carrying the samples 
Proc. of the Second Intl. Conf. on Advances in Mechanical and Automation Engineering - MAE 2015

Copyright $\odot$ Institute of Research Engineers and Doctors, USA .All rights reserved.

ISBN: 978-1-63248-045-3 doi: 10.15224/ 978-1-63248-045-3-37

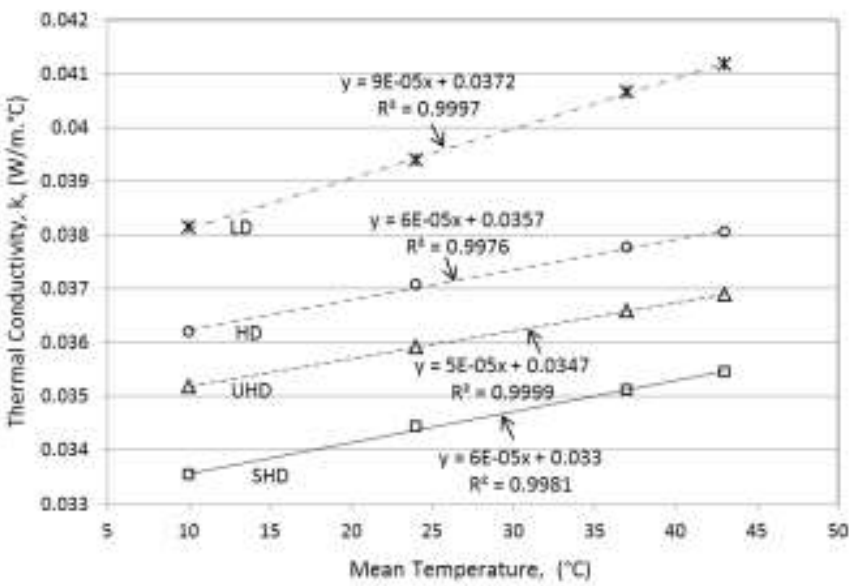

Fig. 7. Change of k-value measurement results of polystyrene with different densities vs. operating temperatures

\section{A. Impact of Thermal Conductivity Variation on the Envelope-induced Cooling Load}

A typical one-story residential building (20x20x3.0) located in Muscat was modeled. The house was assumed to operate at a typical residential load profile. Windows are distributed uniformly over $10 \%$ of the wall area (U-value= $\left.3.339 \mathrm{~W} / \mathrm{m}^{2} \mathrm{~K}\right)$. Dark and light colored surfaces are considered in the simulation. The cooling loads are calculated by using the computer program HAP using the climate data of Muscat.

Carrier's Hourly Analysis Program (HAP) is two powerful tools in one package. HAP provides versatile features for designing HVAC systems for commercial buildings. It also offers powerful energy analysis capabilities for comparing energy consumption and operating costs of design alternatives. By combining both tools in one package significant time savings are achieved. Input data and results from system design calculations can be used directly in energy studies. The calculation of the cooling load has been obtained for July at 23:00.

Table 2 gives the variation of the building envelopeinduced cooling load in ton of refrigeration as a function of the $\mathrm{k}$-values of the insulation material for difference percentage of moisture. The effect of the moisture content on the cooling load required by the space is clearly shown in this table and one can see that the cooling load required by the space increases with the increase of both the moisture content and the operating temperature of the insulation material.

Table 3 shows the change in building envelope-induced cooling load in ton of refrigeration for light and dark external wall colors at different percentages of moisture content at $28^{\circ} \mathrm{C}$. The color of the external walls affects seriously the amount of the cooling load required by the space.

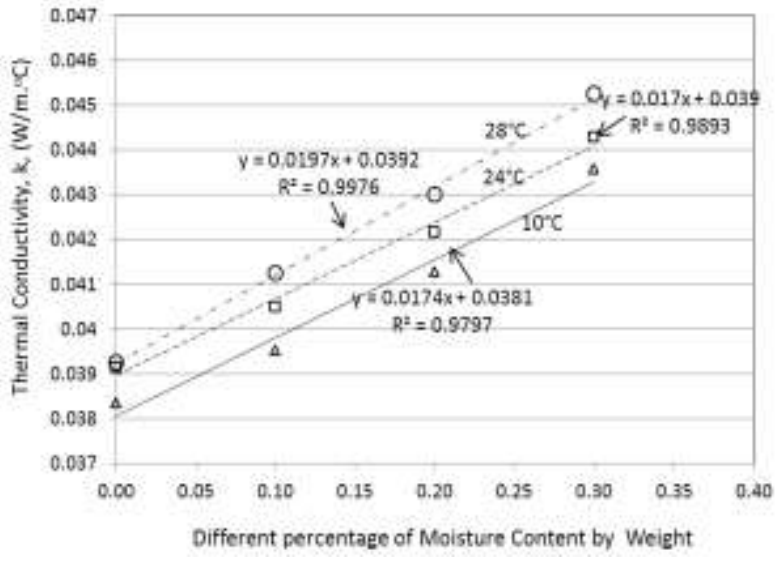

Fig. 8. Best-fit variation of k-values vs. moisture content level at 10,24 , and $28^{\circ} \mathrm{C}$ operating temperature.



Fig. 9. Best-fit relationships of k-value measurement results of LD vs. operating temperatures and different percentages of moisture content by weight

TABLE II. CHANGE IN BUILDING ENVELOPE-INDUCED COOLING LOAD IN TON OF REFRIGERATION DUE TO CHANGE ON THERMAL CONDUCTIVITY OF INSULATION MATERIAL AT 10 AND $28^{\circ} \mathrm{C}$ AND DIFFERENT PERCENTAGES OF MOISTURE CONTENT

\begin{tabular}{|c|c|c|c|c|}
\hline \multirow{2}{*}{$\begin{array}{c}\text { Operating } \\
\text { temperature } \\
{\left[{ }^{\circ} \mathbf{C}\right]}\end{array}$} & 0 & 10 & 20 & 30 \\
\cline { 2 - 5 } & 12.92 (tons) & 12.98 & 13.07 & 13.18 \\
\hline 10 & 12.97 & 13.07 & 13.16 & 13.26 \\
\hline 28 &
\end{tabular}

TABLE III. CHANGE IN BUILDING ENVELOPE-INDUCED COOLING LOAD IN TON OF REFRIGERATION FOR LIGHT AND DARK EXTERNAL WALL COLORS AT DIFFERENT PERCENTAGES OF MOISTURE CONTENT AT $28^{\circ} \mathrm{C}$

\begin{tabular}{|c|c|c|c|c|}
\hline \multirow{2}{*}{$\begin{array}{c}\text { External color } \\
\text { surface }\end{array}$} & \multicolumn{4}{|c|}{ Percentage of moisture content } \\
\cline { 2 - 5 } & 0 & 10 & 20 & 30 \\
\hline Light & 12.27 (tons) & 12.34 & 12.4 & 12.48 \\
\hline Dark & 12.97 & 13.07 & 13.16 & 13.26 \\
\hline Difference [\%] & 5.4 & 5.6 & 5.7 & 5.9 \\
\hline
\end{tabular}




\section{Conclusion}

The impact of thermal conductivity change of polystyrene insulation material due to the operating temperature for different densities has been investigated. Four different densities low density (LD), high density (HD), ultra high density (UHD), and super high density (SHD) have been considered. The thermal conductivity of three samples of each density has been measured at four different operating mean temperatures using a developed experimental apparatus based on the guarded hot plate principle. The result shows that the thermal conductivity of the samples is affected by the change in operating temperature. In all cases, higher temperature leads to higher thermal conductivity. The result also shows that the lower the material density is the higher is the thermal conductivity.

The effect of the moisture content on the k-value of polystyrene insulation with different densities at 10, 24, and $28^{\circ} \mathrm{C}$ was investigated using the developed ultrasonic humidifier apparatus described previously. HD, UHD, and SHD samples are impermeable to water and moisture transfer due to their high densities. Therefore, the study was limited to the LD sample. Indeed, the thermal conductivity of the LD sample increases with the increase of the moisture content and the increase of the operating temperature.

The change of the thermal conductivity of the LD sample in term of the moisture content on the building envelopeinduced cooling load has been calculated. The results shown are for the peak cooling load required by the modeled space on July at 23:00. Although the effect of the moisture content on the peak cooling load seems to be very small, however, this could be significant for a long period of time, a whole year for instance.

Therefore, more accurate data of thermal conductivity of building insulation material would lead to more precise cooling load calculation especially over a long period of time. Then, appropriate selection and precise optimization of the cooling/heating system can be achieved.

The results of this study call for the need to require from thermal insulation material manufacturers to provide the kvalues of their insulation materials at different operating temperatures and moisture content for different densities of the samples to allow building designers to assess accurately the energy requirements of buildings.

\section{Acknowledgment}

This study was supported in part by the internal grant "Investigation of the impact of Temperature and Moisture Contents on Building Insulation Materials Thermal Conductivity", IG-ENG-CAED 13-01, funded by SQU. The author is grateful to Mr. Nilupul Induka Halwalage, technician at $\mathrm{CAE}$ department (SQU) for the measurement procedure done on the samples.

\section{References}

[1] M. Khoukhi and M. Tahat, "Effect of operating temperatures on thermal conductivity of polystyrene insulation material: impact on envelopeinduced cooling load," App. Mech. and Mater., vol. 564, 2014, pp. 315320.

[2] M.A. Abdelrahman and A. Ahmad, "Cost effective use of thermal insulation in hot climates," Bui. Env. vol. 26, 1991, pp. 189-194.

[3] ASHRAE: Handbook of Fundamentals. Atlanta, GA, Chap. 23, 2001.

[4] B.A. Peavy, "A heat transfer note on temperature dependent thermal conductivity," Ther. Ins. Bui. Env., vol. 20, 1996, pp. 79-90.

[5] F. Dominguez-Munoz, B. Anderson, J. Cejudo-Lopez, and Carrillo A. Andres, "Uncertainty in the thermal conductivity of insulation materials," Elev. Inter. IBPSA Conf. Glasgow, Scotland July 27-30, 2009.

[6] A. Budawi, A. Abdou and M. Al-Homoud, "Variations of thermal conductivity of insulation materials under different operating temperatures: impact on envelope-induced cooling load," J. Arch. Eng. December 2002, pp. 125-132.

[7] D.F. Aldrich and RH. Bond, "Thermal performance of rigid cellular foam insulation at subfreezing temperature thermal performance of exterior envelopes of buildings III, ASHRAE/DOE/BTECC Conf., Florida, 2-5 December 1985, pp. 500-509.

[8] K.E. Wilkes and PW. Child, "Thermal performance of fiberglas and cellulose attic insulation. Thermal performance of exterior envelopes of buildings V, ASHRAE/DOE/BTECC/CIBSE Conference, Clear Water Beach, Florida, 7-10 December 1992, pp. 357-367.

[9] A. Al-Hammad, MA. Abdelrahman, W. Grondzik and A. Hawari, "A comparison between Actual and published K-values for Saudi insulation materials," Ther. Ins. Bui. Env., vol. 17, Technical Notes 1994, pp.378385.

[10] G.S. Kochlar and K. Monahar, "Effect of moisture on thermal conductivity of fibers biological insulation materials. Thermal performance of exterior envelopes of buildings VI," ASHRAE/DOE Conference, Florida, 2-5 December 1995, pp. 33-40.

[11] Chyu, M.C., Zeng, X. and L. Ye. "The effect of moisture on the performance of polyurethene insulation used on a district heating and cooling pipe," ASHRAE Tran., vol. 103 (part 1), 1997, pp. 309-317.

[12] Chyu, M.C., Zeng, X. and L. Ye. "Performance of fibers glass pipe insulation subjected to underground water attack," ASHRAE Tran., vol. 103 (part 1), 1997, pp. 303-308.

[13] Chyu, M.C., Zeng, X. and L. Ye. "Effect of undeground water attack on the performance of mineral wool pipe insulation," ASHRAE Tran., vol. 104 (part 2), 1998, pp. 168-175.

[14] I, Budaiwi and A. Abdou, "Effect of thermal conductivity change of moist fibrous insulation on energy performance of buildings under hothumid conditions," Ener. And Buil., vol. 60, 2013, pp. 388-399.

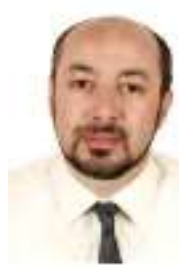

Dr. Maatouk Khoukhi is a faculty member in college of engineering at Sultan Qaboos University. His area of expertise covers wide subjects including solar energy, building sciences and building engineering systems. He published more than 60 journal and conference papers. 